\title{
Waveguide lasers in ytterbium-doped tantalum pentoxide on silicon
}

\author{
A. Aghajani ${ }^{1 *}$, G. S. Murugan ${ }^{1}$, N. P. Sessions ${ }^{1}$, V. Apostolopoulos ${ }^{2}$ and J. S. Wilkinson ${ }^{1}$ \\ ${ }^{1}$ Optoelectronics Research Centre, University of Southampton, Southampton, UK SO17 1BJ \\ ${ }^{2}$ School of Physics and Astronomy, University of Southampton, Southampton, UK SO17 1BJ \\ *Corresponding author: aa15v07@soton.ac.uk \\ Received Month X, XXXX; revised Month X, XXXX; accepted Month X, \\ XXXX; posted Month X, XXXX (Doc. ID XXXXX); published Month X, XXXX

\begin{abstract}
A waveguide laser in an ytterbium doped tantalum pentoxide film is reported. The waveguide is formed of a rib of sputtered tantalum pentoxide on top of oxidized silicon with an over-cladding of silica. Emission at a wavelength of $1025 \mathrm{~nm}$ was achieved with an absorbed pump power threshold and slope efficiency of $\approx 29 \mathrm{~mW}$ and $27 \%$ respectively for a cavity formed by a high reflector mirror and an estimated $12 \%$ Fresnel reflection from the bare end-face at the output. (C) 2015 Optical Society of America
\end{abstract} \\ OCIS Codes: (140.3615) Lasers, ytterbium, (140.3380) Laser materials, (230.7380) Waveguides, channeled,
}

Lasers doped with ytterbium $(\mathrm{Yb})$ ions exhibit long excited-state lifetime yielding high gain efficiency and low pump power thresholds, low quantum defect providing good power-handling ability and low-cost optical pumping using semiconductor sources due to broad absorption at wavelengths near $980 \mathrm{~nm}$. For the realisation of Yb-doped waveguide lasers and amplifiers, amorphous host materials such as silicate [1], phosphate [2,3], bismuthate glasses [4] and $\mathrm{Al}_{2} \mathrm{O}_{3}$ [5] have been studied. Further, crystalline materials such as YAG $[6,7], \mathrm{LiNbO}_{3}[8,9]$, $\mathrm{KGd}\left(\mathrm{WO}_{4}\right)_{2}$ [10-12] and $\mathrm{LiYF}_{4}$ [13] have been similarly researched. Tantalum pentoxide $\left(\mathrm{Ta}_{2} \mathrm{O}_{5}\right)$ is a promising alternative amorphous host material for $\mathrm{Yb}^{3+}$ ions [14] that has been demonstrated as a laser host for neodymium [15] and erbium [16] trivalent rare-earth ions. $\mathrm{Ta}_{2} \mathrm{O}_{5}$ can be used with CMOS fabrication technologies [17], leading to the potential of multi-functional, massproducible, integrated optical circuits on silicon. The material also shows a large third-order non-linearity $\left(\mathrm{n}_{2} \approx\right.$ $7.25 \times 10^{-19} \mathrm{~m}^{2} / \mathrm{W}$ at $\lambda \approx 980 \mathrm{~nm}$ ) [18] with potential for alloptical processing, and a high-refractive index $(\mathrm{n} \approx 2.124$ at $\lambda \approx 980 \mathrm{~nm}$ ) [19] enabling compact photonic circuits with low bend loss. A high index makes possible submicron waveguide mode sizes which are useful for nonlinear interactions and low laser thresholds and also

Table 1. Comparison of properties

\begin{tabular}{l|c|c}
\hline Properties & $\begin{array}{c}\text { Tantalum } \\
\text { pentoxide }\end{array}$ & $\begin{array}{c}\text { Aluminium } \\
\text { oxide [20] }\end{array}$ \\
\hline \hline Refractive index & 2.124 & 1.726 \\
\hline $\begin{array}{l}\text { Third-order non- } \\
\text { linearity } \times 10^{-19} \mathrm{~m}^{2} / \mathrm{W}\end{array}$ & $\begin{array}{c}7.25 \text { at } \lambda \approx 980 \\
\mathrm{~nm}\end{array}$ & $\begin{array}{c}0.31 \text { at } \lambda \approx \\
1064 \mathrm{~nm}\end{array}$ \\
\hline
\end{tabular}

makes possible the development of ring resonators that require tight bend radii. Furthermore, $\mathrm{Ta}_{2} \mathrm{O}_{5}$ offers high transparency and low two-photon absorption in the NIR compared with silicon, better rare-earth compatibility compared with silicon and silicon nitride, and high indexcontrast and large third-order nonlinearity compared with aluminium oxide $\left(\mathrm{n} \approx 1.726 ; \mathrm{n}_{2} \approx 0.31 \times 10^{-19} \mathrm{~m}^{2} / \mathrm{W}\right.$ at $\lambda \approx$ $1064 \mathrm{~nm}$ [20]). As the high nonlinearity is coupled with broad fluorescence bandwidth [14], this material is particularly attractive for the realization of on-chip frequency comb generation and mode-locked lasers.

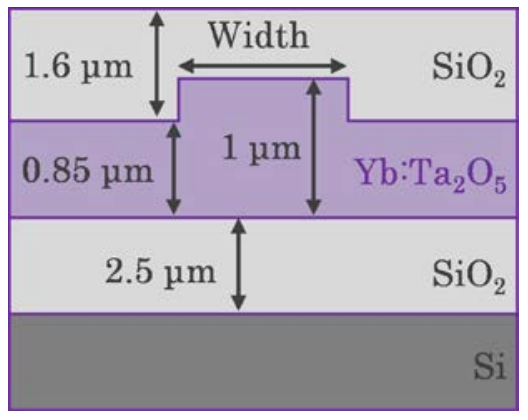

Fig. 1. Schematic of a partially etched rib $\mathrm{Yb}: \mathrm{Ta}_{2} \mathrm{O}_{5}$ waveguide with silica under and over cladding on top of a silicon substrate

In this letter, we present an integrated waveguide laser in $\mathrm{Yb}$-doped $\mathrm{Ta}_{2} \mathrm{O}_{5}\left(\mathrm{Yb}: \mathrm{Ta}_{2} \mathrm{O}_{5}\right)$ on silicon, Fig. 1 including characteristics such as slope efficiency and threshold with respect to absorbed pump power and lasing spectrum. Detailed fabrication procedures, absorption and emission cross-sections and other materials properties were previously reported in [14]. From that study many key properties were established such as fluorescence emission spanning between $990 \mathrm{~nm}$ and $1090 \mathrm{~nm}$ with an estimated peak emission cross-section of $2.9 \pm 0.7 \times 10^{-20}$ $\mathrm{cm}^{2}$ (at $\lambda=976 \mathrm{~nm}$ ) seen in Fig. 2, a peak absorption cross-section of $2.8 \pm 0.2 \times 10^{-20} \mathrm{~cm}^{2}$ (at $\lambda=975 \mathrm{~nm}$ ), and luminescence lifetime of $260 \pm 30 \mu \mathrm{s}$. These values showed that $\mathrm{Yb}: \mathrm{Ta}_{2} \mathrm{O}_{5}$ is a promising material for continuous wave and modelocked lasing. In the present work, rib waveguides in $\mathrm{Yb}: \mathrm{Ta}_{2} \mathrm{O}_{5}$ were designed to be single mode for wavelengths between $970 \mathrm{~nm}$ and $1100 \mathrm{~nm}$, covering pump and signal wavelengths typical for $\mathrm{Yb}$ doped materials [14]. The waveguide design approach assumed a $2.5 \mu \mathrm{m}$ thick oxide layer on the silicon and a thick silica cladding on top of the waveguides to create a high index contrast symmetrical waveguide. A partially-etched rib design [14] was adopted to allow single mode operation 


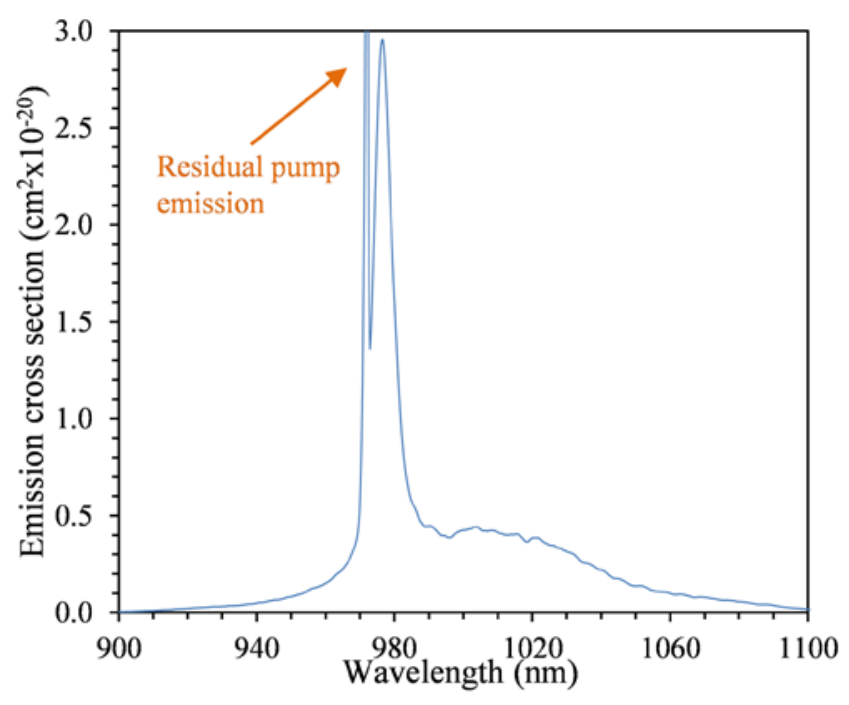

Fig. 2. Emission cross-section of $\mathrm{Yb}^{-} \mathrm{Ta}_{2} \mathrm{O}_{5}$.

with waveguide widths readily fabricated using conventional photolithography, to maximize pump-signal overlap and to minimize waveguide loss due to sidewall roughness; a schematic of the general waveguide design is shown in Fig. 1. A $1 \mu \mathrm{m} \mathrm{Yb}: \mathrm{Ta}_{2} \mathrm{O}_{5}$ waveguide layer height was chosen to provide good confinement of modes within the core layer. The initial waveguide design was established using the method of Soref [21] and confirmed using COMSOL. A shallow etch depth of $150 \mathrm{~nm}$ was selected as a trade-off between tight confinement of propagating modes and loss due to side roughness, leaving an outer slab thickness of $850 \mathrm{~nm}$ as shown in Fig 1. A $1 \mu \mathrm{m}$ thick layer of $\mathrm{Yb}: \mathrm{Ta}_{2} \mathrm{O}_{5}$ was deposited onto a 10 $\mathrm{cm}$ diameter silicon substrate with a $2.5 \mu \mathrm{m}$ thermallygrown silica layer. The $\mathrm{Yb}: \mathrm{Ta}_{2} \mathrm{O}_{5}$ layer was deposited by $\mathrm{RF}$ magnetron sputtering from a powder-pressed $\mathrm{Ta}_{2} \mathrm{O}_{5}$ target doped with $2.5 \mathrm{wt} . \%$ of $\mathrm{Yb}$ oxide $\left(\mathrm{n} \approx 6.2 \times 10^{20} \mathrm{Yb}\right.$ ions $/ \mathrm{cm}^{3}$ ) [14]. The deposition conditions followed closely previous work on $\mathrm{Ta}_{2} \mathrm{O}_{5}$ doped with erbium [22]. Rib waveguide channels for rib widths ranging from $1 \mu \mathrm{m}$ to $10 \mu \mathrm{m}$ were defined in the $\mathrm{Yb}: \mathrm{Ta}_{2} \mathrm{O}_{5}$ layer using standard photolithography and etched by $150 \mathrm{~nm}$ using argon ion beam milling. Subsequently, a $1.6 \mu \mathrm{m}$ thick $\mathrm{SiO}_{2}$ cladding layer was deposited on top of the waveguides using $\mathrm{RF}$ magnetron sputtering. The wafer was then diced and the end-facets were optically polished for laser characterization.

A $10.8 \mathrm{~mm}$ long waveguide chip with parallel end-facets was used for laser measurements. Initially, the laser cavity was formed by reflections from the end-facets alone. The waveguide-air interfaces were estimated to have Fresnel reflectivities of $12 \%$. Subsequently, mirrors were end-butted to the waveguides and held in place by surface tension between the mirror and waveguide end-facet using fluorinert (FC-70, Sigma Aldrich). Lasing was demonstrated by launching a free space collimated laser beam at $\lambda=977 \mathrm{~nm}$ from a Bragg grating stabilized laser source into an end-facet of a $5.4 \mu \mathrm{m}$ wide waveguide using an aspheric lens $(\mathrm{NA}=0.68)$. The light emerging from the output end was collected using another aspheric lens (NA $=0.68$ ) and passed through a set of long pass filters with a cut-off wavelength of $1 \mu \mathrm{m}$ to remove the residual pump radiation before being focused onto a silicon power detector, as shown in Fig. 3.

The $\mathrm{Yb}: \mathrm{Ta}_{2} \mathrm{O}_{5}$ waveguide laser output power and residual pump power were measured with respect to the incident pump power for different mirror and end-facet combinations. Observation of the near-field mode intensity profile at the pump wavelength at the waveguide output was used to ensure efficient pump coupling into the waveguide fundamental mode. The absorbed pump power was deduced from these measurements using the estimated spatial overlap between the waveguide's fundamental mode and the spotsize of the pump beam focused on the waveguide end. The knife edge method [23] was used to determine the FWHM spot-size of the focused pump beam to be $0.81 \mu \mathrm{m}$. The theoretical modal intensity distribution vs rib width has been determined previously [14] and was used in the calculation of the launch system coupling efficiency to give a coupling efficiency of $44 \%$ for a rib width of $5.4 \mu \mathrm{m}$. Figure 4 shows the laser output power vs absorbed pump power for four different mirror configurations. Figure 4a shows the case with the output facet being simply the polished end while the input facet is either the simple polished end or a $>99.9 \%$ (HR) reflector at the lasing wavelength. Figure $4 \mathrm{~b}$ shows the case where the input facet has an HR mirror affixed, while the output coupler (OC) is either $5 \%$ or $10 \%$ (compared with $88 \%$ for a bare end facet). The lasing thresholds, $\mathrm{P}_{\text {th }}$, and slope efficiencies, $\eta_{\mathrm{sl}}$, extracted from Fig 4 are shown in Table 2.

The highest single-ended output power and slope efficiency of $\approx 25 \mathrm{~mW}$ and $\approx 27 \%$ respectively were found to be from the cavity formed from an HR mirror and endfacet of the waveguide, as expected. A single end slope efficiency equation is used to calculate the theoretical slope efficiencies of rib waveguides, as given by Eq. 1

$$
\eta_{s l}=\eta_{p} \frac{\gamma_{1}}{\delta_{i}} \frac{h v_{l}}{h v_{p}}
$$

where $\mathrm{h}$ is Planck's constant, $\mathrm{v}_{\mathrm{l}}$ and $\mathrm{v}_{\mathrm{p}}$ are the lasing $\left(\lambda_{\mathrm{l}}\right.$ $=1025 \mathrm{~nm})$ and pump $\left(\lambda_{\mathrm{p}}=977 \mathrm{~nm}\right)$ frequencies, $\eta_{\mathrm{p}}$ is the fractional pump power contained in the active region (considered unity in this case), and $\delta_{i}$ is the round-trip loss of the laser cavity. The round-trip loss is the sum of the logarithmic internal round-trip cavity loss, $\mathrm{Y}_{\mathrm{i}}=-2^{*}[\ln (1-\mathrm{a})$ $\left.+\ln \left(1-\mathrm{L}_{\mathrm{i}}\right)\right]$ and logarithmic losses of the two cavity mirrors, $\mathrm{Y}_{1}=-\ln \left(1-\mathrm{T}_{1}\right)$ and $\mathrm{Y}_{2}=-\ln \left(1-\mathrm{T}_{2}\right)$ where $\mathrm{T}_{1}$ is the transmission of the output mirror, $\mathrm{T}_{2}$ is the transmission of the input mirror, $\mathrm{L}_{\mathrm{i}}$ is the linear loss of cavity, and $\mathrm{a}$ is the fractional mirror loss which is assumed negligible.

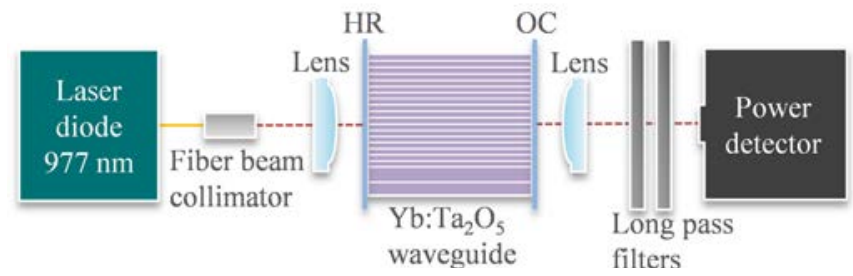

Fig. 3. Experimental set-up for laser characterization of $\mathrm{Yb}: \mathrm{Ta}_{2} \mathrm{O}_{5}$ with high reflector (HR) mirror and output coupler (OC) with top down view of waveguide device. 

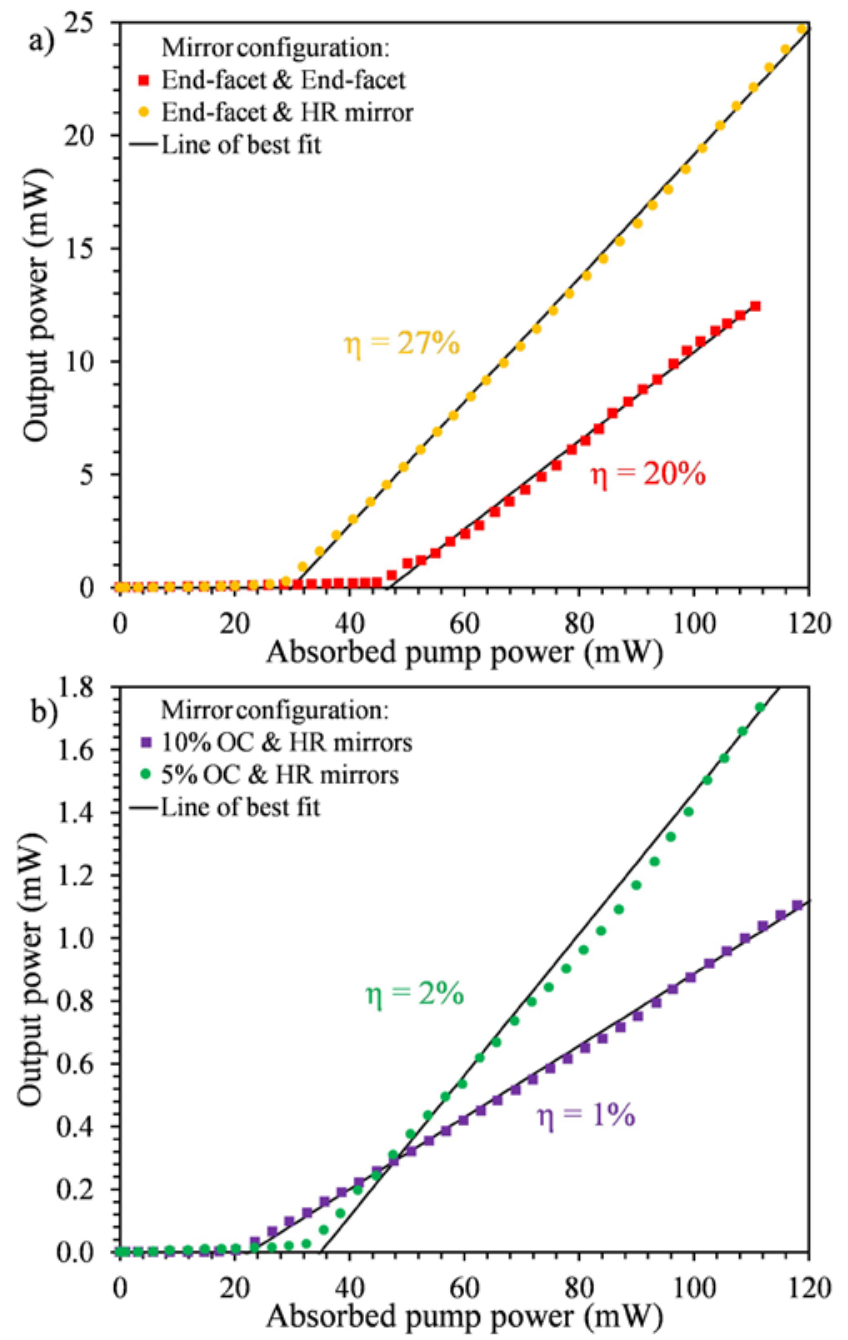

Fig. 4. Laser output power vs absorbed pump power plotted for different mirror configurations with a calculated coupling efficiency of $44 \%$. Mirror configurations used: a) EF/EF \& EF/HR, b) 10\% OC / HR \& 5\% OC / HR.

Table 2. Laser parameters for different mirror configurations $(\mathrm{EF}=$ Bare end-facet)

\begin{tabular}{l|c|c}
\hline Mirror configuration & $\begin{array}{l}\text { Slope efficiency } \\
\eta_{\text {sl }}\end{array}$ & $\begin{array}{l}\text { Threshold } \\
(\mathrm{mW})\end{array}$ \\
\hline \hline $\mathrm{EF} / \mathrm{EF}$ & $20 \pm 1.0 \%$ & $45 \pm 2.0$ \\
\hline $\mathrm{EF} / \mathrm{HR}$ & $27 \pm 1.5 \%$ & $29 \pm 1.5$ \\
\hline $10 \% \mathrm{OC} / \mathrm{HR}$ & $2 \pm 0.1 \%$ & $33 \pm 1.5$ \\
\hline $5 \% \mathrm{OC} / \mathrm{HR}$ & $1 \pm 0.1 \%$ & $21 \pm 1.0$ \\
\hline
\end{tabular}

A Caird analysis [24] was carried out on the measured slope efficiencies shown in Table 2, which led to single trip loss of the waveguide laser cavity of $\approx 3.4 \mathrm{~dB}$. For a system with a single trip intra-cavity loss of $\approx 3.4 \mathrm{~dB}$, due to propagation loss and loss at the waveguide/mirror interfaces, the slope efficiencies were found to be $35 \%$, $55 \%, 6 \%$ and $3 \%$ for the $\mathrm{EF} / \mathrm{EF}, \mathrm{EF} / \mathrm{HR}, 10 \% \mathrm{OC} / \mathrm{HR}$, and $5 \%$ OC/HR resonator configurations, respectively [25]. The slope efficiencies are systematically lower than predicted by Eq. 1. The reduced slope efficiencies may be (i) because our estimation of absorbed pump power assumes perfect alignment of pump beam with a very small waveguide mode, (ii) because of pump loss

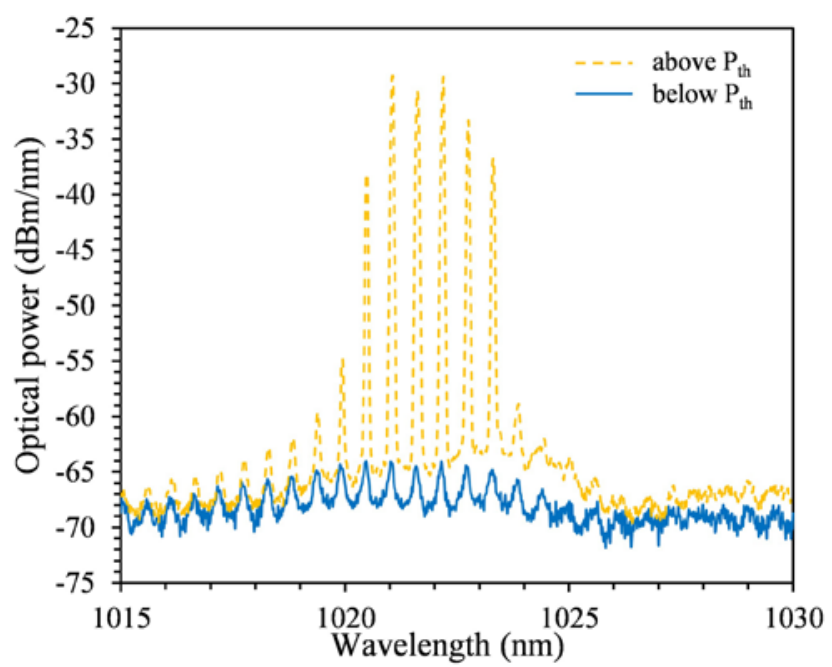

Fig. 5. Lasing spectrum of $\mathrm{Yb}: \mathrm{Ta}_{2} \mathrm{O}_{5}$ focusing around region lasing occurs with lasing spectrum development just below (solid line) and above (dashed line) threshold for cavity form with a $\mathrm{HR}$ mirror and a 5\% OC.

competing with pump absorption or (iii) because of nonunity quantum efficiency. Figure 5 shows the $\mathrm{Yb}: \mathrm{Ta}_{2} \mathrm{O}_{5}$ waveguide laser output spectrum just below and above threshold for a cavity formed with a HR mirror and a 5\% OC with lasing peaks occurring between $1015 \mathrm{~nm}$ and $1030 \mathrm{~nm}$. The spectrum shows multiple lasing peaks occurring within the $1015 \mathrm{~nm}$ and $1030 \mathrm{~nm}$ region which do not correspond with the free spectral range associated with the length of the laser cavity (the individual longitudinal modes are not resolved by the OSA). The optical path length (in air) which would correspond to the observed separation of the laser emission peaks is 0.89 $\mathrm{mm}$. This behaviour is most likely due to modal beating in the waveguide which, for this width, is multimode at the emission wavelength.

In conclusion, we have demonstrated an integrated $\mathrm{Yb}: \mathrm{Ta}_{2} \mathrm{O}_{5}$ waveguide laser on silicon, fabricated by $\mathrm{RF}$ magnetron sputtering, conventional photolithography and argon ion beam milling, suitable for mass-manufacture using conventional CMOS processes. Lasing was observed between $1015 \mathrm{~nm}$ and $1030 \mathrm{~nm}$ when end-pumped with a $977 \mathrm{~nm}$ laser diode. Both mirrored and mirror-less cavities were characterized, with reflections occurring off the polished end-facets in the latter cases. The highest output power of $25 \mathrm{~mW}$ at a wavelength of $1025 \mathrm{~nm}$ was achieved with an absorbed pump power of $120 \mathrm{~mW}$ for a cavity formed by a high reflector mirror and an estimated $12 \%$ Fresnel reflection at the output. In this case, the absorbed pump power threshold and slope efficiency were measured to be $\approx 29 \mathrm{~mW}$ and $\approx 27 \%$ respectively. Future work will focus on mode-locked lasers with high repetition rate, for realisation of frequency combs.

The authors acknowledge the UK EPSRC for a studentship and for support under platform grant EP/J008052/1 "Integrated Photonic Materials and Devices". All data supporting this study are openly available from the University of Southampton repository at http://dx.doi.org/10.5258/SOTON/376707. 
References

1. C. Florea and K.A. Winick, J. Lightwave Technol. 17(8), 1593-1601 (1999).

2. M. Ams, P. Dekker, G.D. Marshall and M.J. Withford, Opt. Lett. 34(3), 247- 249 (2009).

3. A.A. Lagatsky, A. Choudhary, P. Kannan, D.P. Shepherd, W. Sibbett and C.T.A. Brown, Opt. Express 21(17), 19608-19614 (2013).

4. R. Mary, S.J. Beecher, G. Brown, R.R. Thomson, D. Jaque, S. Ohara and A.K. Kar, Opt. Lett. 37(10), 1691-1693 (2012).

5. E.H. Bernhardi, H.A.G.M. van Wolferen, K. Wörhoff, R.M. de Ridder and M. Pollnau, Opt. Lett. 36(5), 603-605 (2011).

6. D.C. Hanna, J.K. Jones, A.C. Large, D.P. Shepherd, A.C. Tropper, P.J. Chandler, M.J. Rodman, P.D. Townsend and L. Zhang, Opt. Commun. 99(3-4), 211-215 (1993).

7. J. Siebenmorgen, T. Calmano, K. Petermann and G. Huber, Opt. Express 18(5), 16035-16041 (2010).

8. J.K. Jones, J.P. de Sandro, M. Hempstead, D.P. Shepherd, A.C. Large, A.C. Tropper and J.S. Wilkinson, Opt. Lett. 20(13), 1477-1479 (1995).

9. M. Fujimura, H. Tsuchimoto and T. Suhara, IEEE Photon. Technol. Lett. 17(1), 130-132 (2005).

10. D. Geskus, S. Aravazhi, E. Bernhardi, C. Grivas, S. Harkema, K. Hametner, D. Gunther, K. Wörhoff and M. Pollnau, Laser Physics Letters 6(11), 800-805 (2009).

11. F.M. Bain, A.A. Lagatsky, R.R. Thomson, N.D. Psaila, N.V. Kuleshov, A.K. Kar, W. Sibbett and C.T.A. Brown, Opt. Express 17(25), 2241722422 (2009).

12. A. Choudhary, W. Bolaños, P. Kannan, J.J. Carvajal, M. Aguilo, F. Diaz, and D.P. Shepherd, "Low-threshold, mirrorless emission at $981 \mathrm{~nm}$ in an $\mathrm{Yb}, \mathrm{Gd}, \mathrm{Lu}: \mathrm{KYW}$ inverted rib waveguide laser," Conference on Solid State Lasers XXII - Technology and Devices, San Francisco, USA (2013).

13. W. Bolaños, F. Starecki, A. Braud, J.-L. Doualan, R. Moncorgé and P. Camy, Opt. Lett. 38(24), 5377-5380 (2013).
14. A. Aghajani, G. Murugan, N. Sessions, S. Pearce, V. Apostolopoulos, and J. Wilkinson, Opt. Mater. Express 4, 1505-1514 (2014).

15. B. Unal, M. C. Netti, M. A. Hassan, P. J. Ayliffe, M. D. B. Charlton, F. Lahoz, N. M. B. Perney, D. P. Shepherd, C.-Y. Tai, J. S. Wilkinson and G. J. Parker, J. Quantum Electron. 41, 1565 - 1573 (2005).

16. A. Z. Subramanian, C. J. Oton, D. P. Shepherd and J. S. Wilkinson, Photon. Technol. Lett. 22(21), 1571-1573 (2010).

17. C. Chaneliere, J.L. Autran, R.A.B. Devine and B. Balland, Materials Science \& Engineering R-Reports 22(6), 269-322 (1998).

18. C. Y. Tai, J. S. Wilkinson, N. M. B. Perney, M. C. Netti, F. Cattaneo, C. E. Finlayson and J. J. Baumberg, Opt. Express 12(21), 5110 -5116 (2004).

19. A. Subramanian, "Tantalum pentoxide waveguide amplifier and laser for planar lightwave circuits," Ph.D. thesis, University of Southampton, UK (2011).

20. Demetrios N. Christodoulides, Iam Choon Khoo, Gregory J. Salamo, George I. Stegeman, and Eric W. Van Stryland, Adv. Opt. Photon. 2(1), 60-200 (2010).

21. R. Soref, J. Schmidtchen and K. Petermann, J. Quantum Electron. 27, 1971-1974 (1991).

22. A. Z. Subramanian, G. S. Murugan, M. N. Zervas, and J. S. Wilkinson, J. Lightwave Technol. 30(10), 1455-1462 (2012).

23. J. Magnes, D. Odera, J. Hartke, M. Fountain, L. Florence, and V. Davis, arXiv preprint physics/0605102 (2006).

24. J. Caird, S. Payne, P. Staber, A. Ramponi, L. Chase, W. Krupke, IEEE J. Quantum Electron. 24(6), 1077-1099 (1988).

25. M. J. F. Digonnet and C. J. Gaeta, Appl. Opt. 24, 333-342 (1985). 
Full Citation listing

1. C. Florea and K.A. Winick, "Ytterbium-doped glass waveguide laser fabricated by ion-exchange," J. Lightwave Technol. 17(8), 1593-1601 (1999).

2. M. Ams, P. Dekker, G.D. Marshall and M.J. Withford, "Monolithic $100 \mathrm{~mW}$ Yb waveguide laser fabricated using the femtosecond-laser direct-write technique," Opt. Lett. 34(3), 247- 249 (2009).

3. A.A. Lagatsky, A. Choudhary, P. Kannan, D.P. Shepherd, W. Sibbett and C.T.A. Brown, "Fundamentally mode-locked, femtosecond waveguide oscillators with multi-gigahertz repetition frequencies up to $15 \mathrm{GHz}$," Opt. Express 21(17), 1960819614 (2013).

4. R. Mary, S.J. Beecher, G. Brown, R.R. Thomson, D. Jaque, S. Ohara and A.K. Kar, "Compact, highly efficient ytterbium doped bismuthate glass waveguide laser," Opt. Lett. 37(10), 1691-1693 (2012).

5. E.H. Bernhardi, H.A.G.M. van Wolferen, K. Wörhoff, R.M. de Ridder and M. Pollnau, "Highly efficient, low-threshold monolithic distributed-Bragg-reflector channel waveguide laser in Al2O3:Yb3+,” Opt. Lett. 36(5), 603-605 (2011).

6. D.C. Hanna, J.K. Jones, A.C. Large, D.P. Shepherd, A.C. Tropper, P.J. Chandler, M.J. Rodman, P.D. Townsend and L. Zhang, "Quasi 3-level 1.03um laser operation of a planar ion-implanted Yb-YAG waveguide," Opt. Commun. 99(3-4), 211215 (1993).

7. J. Siebenmorgen, T. Calmano, K. Petermann and G. Huber, "Highly efficient Yb:YAG channel waveguide laser written with a femtosecond laser," Opt. Express 18(5), 16035-16041 (2010).

8. J.K. Jones, J.P. de Sandro, M. Hempstead, D.P. Shepherd, A.C. Large, A.C. Tropper and J.S. Wilkinson, "Channel waveguide laser at 1 $\mu \mathrm{m}$ in Yb-diffused LiNbO3," Opt. Lett. 20(13), 1477-1479 (1995).

9. M. Fujimura, H. Tsuchimoto and T. Suhara, "Yb-diffused LiNbO3 annealed/proton-exchanged waveguide lasers," IEEE Photon. Technol. Lett. 17(1), 130-132 (2005).

10. D. Geskus, S. Aravazhi, E. Bernhardi, C. Grivas, S. Harkema, K. Hametner, D. Gunther, K. Wörhoff and M. Pollnau, "Low" threshold, highly efficient Gd3+, Lu3+ co-doped KY(WO4)(2):Yb3+ planar waveguide lasers," Laser Physics Letters 6(11), 800-805 (2009).

11. F.M. Bain, A.A. Lagatsky, R.R. Thomson, N.D. Psaila, N.V. Kuleshov, A.K. Kar, W. Sibbett and C.T.A. Brown, "Ultrafast laser inscribed Yb:KGd(WO4)2 and Yb:KY(WO4)2 channel waveguide lasers,” Opt. Express 17(25), 22417-22422 (2009). A. Choudhary, W. Bolaños, P. Kannan, J.J. Carvajal, M. Aguilo, F. Diaz, and D.P. Shepherd, "Low-threshold, mirrorless emission at $981 \mathrm{~nm}$ in an $\mathrm{Yb}, \mathrm{Gd}$, Lu:KYW inverted rib waveguide laser," Conference on Solid State Lasers XXII Technology and Devices, San Francisco, USA (2013).

13. W. Bolaños, F. Starecki, A. Braud, J.-L. Doualan, R. Moncorgé and P. Camy, "2.8W end-pumped Yb3+:LiYF4 waveguide laser," Opt. Lett. 38(24), 5377-5380 (2013).

14. A. Aghajani, G. Murugan, N. Sessions, S. Pearce, V. Apostolopoulos, and J. Wilkinson, "Spectroscopy of ytterbium-doped tantalum pentoxide rib waveguides on silicon" Opt. Mater. Express 4, 1505-1514 (2014).

15. B. Unal, M. C. Netti, M. A. Hassan, P. J. Ayliffe, M. D. B. Charlton, F. Lahoz, N. M. B. Perney, D. P. Shepherd, C.-Y. Tai, J. S. Wilkinson and G. J. Parker, "Neodymium-doped tantalum pentoxide waveguide lasers," J. Quantum Electron. 41, 1565 1573 (2005).

16. A. Z. Subramanian, C. J. Oton, D. P. Shepherd and J. S. Wilkinson, "Erbium-doped waveguide laser in tantalum pentoxide," Photon. Technol. Lett. 22(21), 1571-1573 (2010).

17. C. Chaneliere, J.L. Autran, R.A.B. Devine and B. Balland, "Tantalum pentoxide (Ta2O5) thin films for advanced dielectric applications," Materials Science \& Engineering R-Reports 22(6), 269-322 (1998).

18. C. Y. Tai, J. S. Wilkinson, N. M. B. Perney, M. C. Netti, F. Cattaneo, C. E. Finlayson and J. J. Baumberg, "Determination of nonlinear refractive index in a Ta2O5 rib waveguide using self-phase modulation," Opt. Express 12(21), 5110 -5116 (2004).

19. A. Subramanian, "Tantalum pentoxide waveguide amplifier and laser for planar lightwave circuits," Ph.D. thesis, University of Southampton, UK (2011).

20. Demetrios N. Christodoulides, Iam Choon Khoo, Gregory J. Salamo, George I. Stegeman, and Eric W. Van Stryland, "Nonlinear refraction and absorption: mechanisms and magnitudes," Adv. Opt. Photon. 2(1), 60-200 (2010).

21. R. Soref, J. Schmidtchen and K. Petermann, "Large single-mode rib waveguides in GeSi-Si and Si-on-SiO2," J. Quantum Electron. 27, 1971-1974 (1991).

A.Z. Subramanian, G.S. Murugan, M.N. Zervas, and J.S. Wilkinson, "Spectroscopy, modeling and performance of erbiumdoped Ta2O5 waveguide amplifiers," J. Lightwave Technol. 30(10), 1455-1462 (2012). J. Magnes, D. Odera, J. Hartke, M. Fountain, L. Florence, and V. Davis, "Quantitative and Qualitative Study of Gaussian Beam Visualization Techniques," arXiv preprint physics/0605102 (2006). J. Caird, S. Payne, P. Staber, A. Ramponi, L. Chase, W. Krupke, "Quantum electronic properties of the Na/sub 3/Ga/sub 2/Li/sub 3/F/sub 12/:Cr/sup 3+/ laser,” IEEE J. Quantum Electron. 24(6), 1077-1099 (1988). 342 (1985). 